University of Nebraska - Lincoln

DigitalCommons@University of Nebraska - Lincoln

8-2009

\title{
Regional Study of No-Till Impacts on Near-Surface Aggregate Properties that Influence Soil Erodibility
}

\author{
Humberto Blanco-Canqui \\ Kansas State University, hblanco2@unl.edu \\ Maysoon M. Mikha \\ USDA-ARS, Central Great Plains Research Station, Akron, CO, maysoon.mikha@usda.gov
}

J. G. Benjamin

USDA-ARS, Joseph.Benjamin@ars.usda.gov

L. R. Stone

Kansas State Univ. Manhattan, KS

A. J. Schlegel

Kansas State Univ. Southwest Research-Extension Center Tribune, KS

See next page for additional authors

Follow this and additional works at: https://digitalcommons.unl.edu/panhandleresext

Part of the Agriculture Commons

Blanco-Canqui, Humberto; Mikha, Maysoon M.; Benjamin, J. G.; Stone, L. R.; Schlegel, A. J.; Lyon, Drew J.; Vigil, M. F.; and Stahlman, P. W., "Regional Study of No-Till Impacts on Near-Surface Aggregate Properties that Influence Soil Erodibility" (2009). Panhandle Research and Extension Center. 5.

https://digitalcommons.unl.edu/panhandleresext/5

This Article is brought to you for free and open access by the Agricultural Research Division of IANR at DigitalCommons@University of Nebraska - Lincoln. It has been accepted for inclusion in Panhandle Research and Extension Center by an authorized administrator of DigitalCommons@University of Nebraska - Lincoln. 


\section{Authors}

Humberto Blanco-Canqui, Maysoon M. Mikha, J. G. Benjamin, L. R. Stone, A. J. Schlegel, Drew J. Lyon, M. F. Vigil, and P. W. Stahlman 


\section{Regional Study of No-Till Impacts on Near-Surface Aggregate Properties that Influence Soil Erodibility}

\author{
Humberto Blanco-Canqui* \\ Kansas State Univ. \\ Agric. Research Center-Hays \\ 1232 240th Ave. \\ Hays, KS 67601-9228
}

M. M. Mikha

J. G. Benjamin

USDA-ARS

Central Great Plains Research Station

Northern Plains Area

$40335 \mathrm{Rd}$. GG

Akron, CO 80720

\section{R. Stone}

Dep. of Agronomy

Kansas State Univ.

Manhattan, KS 66506

\section{A. J. Schlegel \\ Kansas State Univ. \\ Southwest Research-Extension Center \\ Tribune, KS 67879 \\ D. J. Lyon \\ Univ. of Nebraska-Lincoln, \\ Panhandle Research and Extension Center 4502 Ave. I \\ Scottsbluff, NE 69391}

\section{F. Vigil \\ USDA-ARS \\ Central Great Plains Research Station \\ Northern Plains Area \\ 40335 Rd. GG \\ Akron, CO 80720}

\section{P. W. Stahlman}

Kansas State Univ.

Agric. Research Center-Hays

1232 240th Ave.

Hays, KS 67601-9228
The extent to which tillage systems modify the near-surface soil aggregate properties affecting soil's susceptibility to erosion by water and wind is not well understood. We hypothesized that an increase in soil organic carbon (SOC) content with conservation tillage systems, particularly no-till (NT), may improve near-surface soil aggregate properties that influence soil erodibility. This regional study assessed changes in aggregate resistance to raindrops, dry aggregate wettability, and dry aggregate stability as well as their relationships with changes in SOC content. Four long-term (>19 yr) tillage systems including moldboard plow (MP), conventional till (CT), reduced till (RT), and NT were chosen across the central Great Plains at Hays and Tribune, KS, Akron, CO, and Sidney, NE. The kinetic energy (KE) of raindrops required to disintegrate 4.75 - to 8 -mm aggregates from NT soils equilibrated at -0.03 and $-155 \mathrm{MPa}$ matric potential was between two and seven times greater than that required for MP and CT soils in the 0 - to 2-cm depth in all soils. At the same depth, the water drop penetration time (WDPT) in aggregates from NT soils was four times greater at Akron and Hays and seven times greater at Sidney and Tribune compared with that in plowed soils. Aggregates from NT soils were more stable under rain and less wettable than those from plowed soils particularly in the surface 0 to $5 \mathrm{~cm}$, but RT had lesser beneficial effects than NT management. The SOC content increased with NT over MP and CT and explained 35\% of the variability across soils in aggregate wettability and $28 \%$ of the variability in resistance to raindrops in the 0 - to $2-\mathrm{cm}$ depth. Aggregate wettability explained $47 \%$ of the variability across soils in KE of raindrops required for the disintegration of aggregates. No-till management did not affect dry aggregatesize distribution and stability except at Akron where mean weight diameter (MWD) in RT and NT was 50\% lower than in MP management in the 0- to 2-cm depth. Aggregates in MP and CT soils were either stronger or equally strong when dry but less stable when wet than in NT soils. Overall, NT farming enhanced near-surface aggregate properties affecting erosion by water but had small or no effects on dry aggregate stability.

Abbreviations: CT, conventional till; KE, kinetic energy; MP, moldboard plow; MWD, mean weight diameter; NT, no-till; RT, reduced till; SOC, soil organic carbon; WDPT, water drop penetration time.

Characterization of near-surface soil aggregate structural properties such as aggregate-size distribution, stability, and aggregate wettability is crucial to predict soil erosion potential, structural development, soil-water-air-heat fluxes, and SOC dynamics. Information on changes in these dynamic aggregate properties is particularly critical to the understanding of vulnerability of a soil to erosion. In fact, knowledge of the resistance of near-surface soil aggregates to the erosive forces of wind and rain is critical in determining the extent to which a soil will erode. This is especially important in semiarid regions such as the Great Plains where low precipitation, high evaporation, and variable and low biomass production in interaction with intensive tillage can alter aggregate properties and accelerate soil's susceptibility to wind and water erosion.

Do the soils managed under various scenarios of tillage systems for several decades develop different or equal susceptibilities to erosion by water or wind? To what extent does NT management reduce soil's susceptibility to water and wind erosion in semiarid regions? The answer to these questions depends primarily on the knowledge of tillage-induced changes in nearsurface soil aggregate characteristics. Specifically, dry aggregatesize distribution and stability are sensitive indicators of soil erodibility by wind (Merrill et al., 1999). Data on these parameters are indeed needed to compute the most wind-erodible fraction 
(particles $<0.80 \mathrm{~mm}$ diam.) of soils (Chepil, 1954). Similarly, the amount of soil detached by rain is a function of the ability of surface soil aggregates to withstand the erosive impacts of raindrops. Aggregate disintegration by raindrops can be better understood by assessing the stability of discrete aggregates rather than a group of aggregates (Mbagwu and Bazzoffi, 1998). The erosive power of impacting raindrops is much greater than that of runoff or flowing water because of their higher terminal velocity (Hudson, 1995). Aggregate stability must thus be determined under both flowing water (e.g., wet-sieving approach; Nimmo and Perkins, 2002) and impacting raindrops to understand the differential erosive impacts of rain and runoff. Moreover, tests on aggregate stability should be performed on aggregates equilibrated at various matric potentials to portray different field soil water contents that differently influence soil erodibility (BlancoCanqui et al., 2007).

While benefits of NT for increasing capture and retention of precipitation and intensification of cropping systems are well recognized, its impacts on near-surface aggregate structural properties are not well understood. Previous studies have shown that NT management may or may not increase soil aggregate stability over plowed systems. On a silt loam in western Kansas, Layton et al. (1993) observed that dry aggregates in NT soils were smaller and less stable than in CT soils in some years. Similarly, McVay et al. (2006) reported that percentage of water-stable aggregates in NT did not differ from that in CT and RT management for two silt loams in western Kansas. Pikul et al. (2006) found that RT with intensive cropping increased MWD of dry aggregates compared with CT only in two of eight soils in the Great Plains. The mixed effects of NT management impacts on aggregate stability warrant additional research.

By leaving crop residues on the soil surface and minimizing soil disturbance, RT and NT practices often increase SOC content (McVay et al., 2006). This increase in SOC may lead to improved stability of aggregates over CT systems because the SOCenriched materials provide organic binding agents to soil that coalesce microaggregates into stable macroaggregates (Tisdall and Oades, 1982; Blanco-Canqui and Lal, 2004). No-till induced increases in SOC may also slightly reduce the rate of wettability or water entry into aggregates in some soils (Hallett et al., 2001). Films of SOC-enriched organic compounds can coat soil aggregates, imparting some hydrophobic properties (Ellerbrock et al., 2005; Blanco-Canqui and Lal, 2009). While excessive soil water repellency (e.g., fire-affected forest soils) can reduce water infiltration and increase runoff rates (DeBano, 2000), a slight reduction of wettability in cultivated soils is beneficial to reduce the extent at which a soil erodes by reducing rapid slaking of aggregates (Chenu et al., 2000; Hallett et al., 2001; Blanco-Canqui and Lal, 2009). Changes in dry aggregate stability, resistance to raindrops, and particularly wettability, which affect soil detachment during erosion, and their relations to changes in SOC content under different scenarios of tillage management have not been well documented for soils in the central Great Plains. Benjamin et al. (2008) observed that SOC content was not correlated with macroaggregates in the 2 - to 18 -cm soil depth but was positively correlated in the 20- to $37-\mathrm{cm}$ depth in an intensively cropped silt loam in eastern Colorado. Interactions of SOC and clay content (e.g., soil mixing) may influence surface aggregate dynamics (Wagner et al., 2007).
Literature reviewed herein shows that despite its critical importance, information on near-surface aggregate structural properties influencing soil water and wind erodibility under long-term NT systems across principal soils in the central Great Plains is limited. It also shows that previous studies on soil structural properties have mostly focused on single soils or point measurements and have not integrated information across soils on a regional scale. Furthermore, very few studies have examined the statistical relationships of NT-induced increases in SOC with near-surface aggregate properties affecting soil erodiblity across a range of soils. We hypothesized that long-term NT systems induce significant changes in near-surface soil aggregate properties and that changes in SOC mostly explain the NT-induced differences in aggregate properties. Thus, the objectives of this study were to quantify changes in aggregate properties (e.g., size distribution, stability, resistance to raindrops, and wettability) and study their relationships to $\mathrm{SOC}$ and soil particle-size fractions under long-term (>19 yr) NT systems as compared with CT and RT in the central Great Plains. This study differs from previous studies in that it uniquely assesses the impacts of various longterm NT management systems on near-surface soil aggregates properties on a regional scale.

\section{MATERIALS AND METHODS Study Site Descriptions}

Four ongoing and representative long-term ( $>19$ yr) tillage experiments across the central Great Plains were selected for this study (Table 1). The field sites were located at Akron, CO, Sidney, NE, and Hays and Tribune, KS. These long-term experiments were managed under the same tillage and cropping system since the start of the experiments and thus were considered suitable for discerning the long-term impacts of management on near-surface aggregate properties affecting soil erodibility. Mean annual precipitation varies among sites from 413 to 580 $\mathrm{mm}$ (Table 1 ). The soils are very deep and formed under loess or loess mixed with alluvium and have gentle slopes $(<1 \%)$ with high risks of wind erosion and low risks of water erosion. Information on the specific location, precipitation amount, soil characteristics, and management for each study site is presented in Table 1.

The tillage systems were established in a randomized complete block design at each site with three replications at Akron and Sidney and four replications at Hays and Tribune. There were three tillage treatments at each site except Akron, where there were four (Table 1). Tillage type and intensities varied among sites. The MP treatment, which was practiced at Akron and Sidney, was plowed with a moldboard plow. The CT treatment used a sweep plow at Akron and Tribune and a tandem disk at Hays. Similarly, tillage tools used for RT differed among sites. Within each site, RT differed from the CT treatment in that it received fewer annual tillage operations. For example, at Tribune, RT received about half the number of tillage operations of CT. The NT treatment was not tilled at any site and weeds were controlled using herbicides. In this study, for discussion purposes, tillage intensity was considered more important than tillage type. Tillage intensities were in the order of: MP $>\mathrm{CT}>\mathrm{RT}>\mathrm{NT}$ at Akron, $\mathrm{CT}>\mathrm{RT}>\mathrm{NT}$ at Hays and Tribune, and $\mathrm{MP}>\mathrm{RT}>\mathrm{NT}$ at Sidney. Where differences in measured soil parameters between MP and CT were not significant, MP and CT were termed "plowed" soils. Because of differences in tillage type among soils, results were discussed by soil. The crop rotations were common to the region and included winter wheat [Triticum aestivum (L.)]-grain sorghum [Sorghum bicolor (L.) Moench]-fallow at Hays and Tribune and 
winter wheat-fallow at Akron and Sidney. Further details on soil management for the experimental sites are discussed by Lyon et al. (1998) and McVay et al. (2006).

\section{Soil Sampling and Data Analyses}

Soil samples were collected from each treatment plot at each site for the 0 - to 2-, 2- to 5-, and 5- to $10-\mathrm{cm}$ soil depth intervals for the determination of aggregate resistance to raindrops, wettability, and dry aggregate stability in late summer 2008. Soil samples were collected from the plots that were under fallow phase of the rotations at the four sites. Samples were air dried at $20^{\circ} \mathrm{C}$ for $48 \mathrm{~h}$, gently crushed, and sieved through sieves of 4.75 - and 8 -mm mesh to obtain 4.75- to 8-mm diam. aggregates for determination of aggregate properties.

Aggregate resistance to raindrops was determined using a raindrop simulator (Al-Durrah and Bradford, 1981; Blanco-Canqui et al., 2007). The simulator consisted of a Mariotte bottle connected to a burette installed at a 2-m height to form raindrops $5.5 \pm 0.03 \mathrm{~mm}$ diam. and $0.13 \pm 0.03 \mathrm{~g}$ in mass with terminal velocity of $3.7 \pm 0.1 \mathrm{~m} \mathrm{~s}^{-1}$. The simulated raindrops struck an individual 4.75- to 8-mm aggregate placed on a 1-mm mesh sieve. Raindrops struck the same spot on each aggregate and no significant raindrop drift occurred during fall. Aggregates for the raindrop test were equilibrated to $-155 \mathrm{MPa}$ (air-dry conditions) soil water matric potential $(\psi)$. A separate set of aggregates from the 0 - to $2-\mathrm{cm}$ soil depth interval was equilibrated at -0.03 MPa $\psi$ using a pressure plate extractor (Dane and Hopmans, 2002). The matric potential of $-155 \mathrm{MPa}$ corresponding to airdry aggregates was computed from the constant temperature of $20^{\circ} \mathrm{C}$ and relative humidity of $32 \%$ (Munkholm and Kay, 2002) using Eq. [1]:

$$
\Psi=R T / M \ln \left(p / p_{0}\right)=-155 \mathrm{Jkg}^{-1}=-155 \mathrm{MPa}[1]
$$

where $R$ is the molar gas (air) constant $\left(\mathrm{J} \mathrm{mol}^{-1} \mathrm{~K}^{-1}\right), T$ is the temperature $(\mathrm{K}), M$ is the molar mass of gas $(\mathrm{mol})$, and $p$ is the water vapor pressure potential $(\mathrm{kPa})$ at $T$, and $p_{0}$ is water vapor pressure $(\mathrm{kPa})$ at the reference temperature. The ratio of pressures $\left(p / p_{0}\right)$ is equal to relative humidity. Water in the Mariotte bottle was at $22 \pm 0.4^{\circ} \mathrm{C}$ during the measurements. The number of simulated raindrops required to disintegrate the individual aggregate and completely pass the disintegrated particles through the 1-mm mesh sieve was used as criteria for the determination of aggregate resistance to raindrops across all tillage treatments. The recorded number of raindrops was converted to KE using Eq. [2]:

$$
\mathrm{KE}=\sum \frac{1}{2} m v^{2}
$$

where $m$ is mass (g) of a raindrop and $v$ is terminal velocity $\left(\mathrm{cm} \mathrm{h}^{-1}\right)$.

Wettability of soil aggregates was also determined on 4.75- to 8-mm air-dry aggregates using the water drop penetration time (WDPT) method (Letey et al., 2000). The test consisted of placing a drop of deionized water on top of individual aggregates by a micro-syringe and recording time (s) required for the drop to completely enter into the

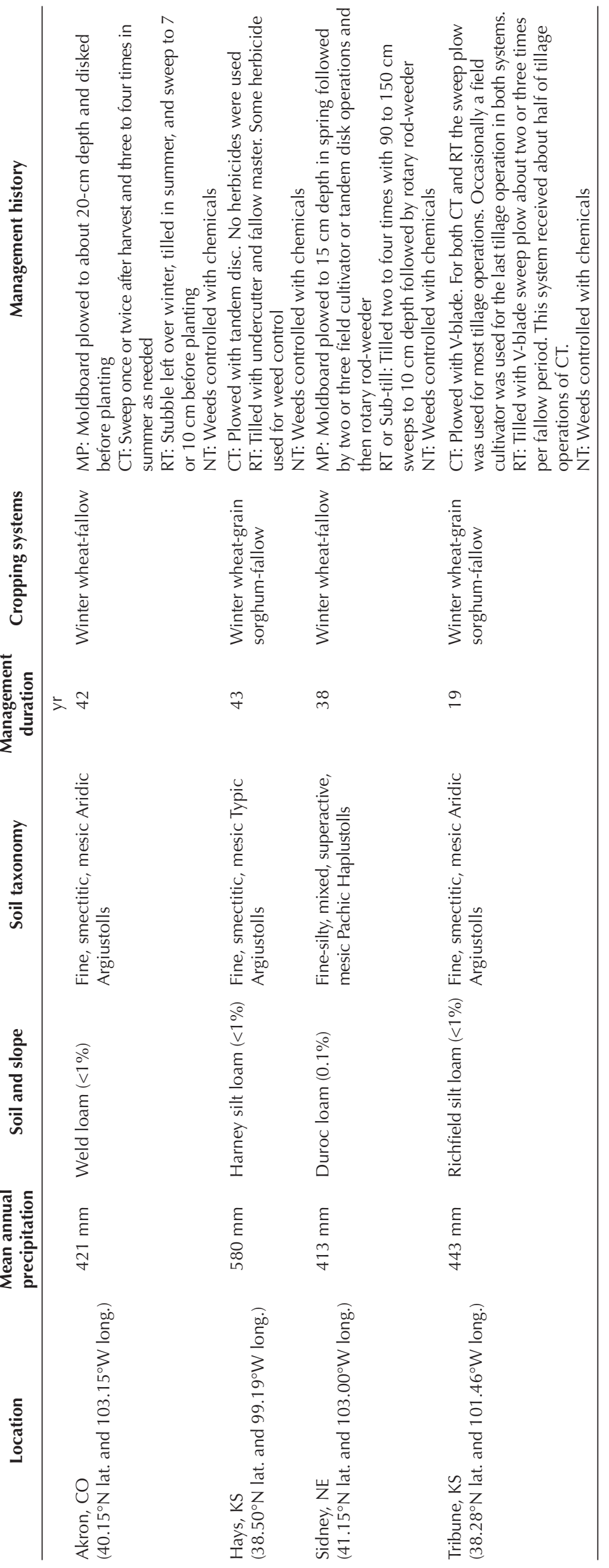



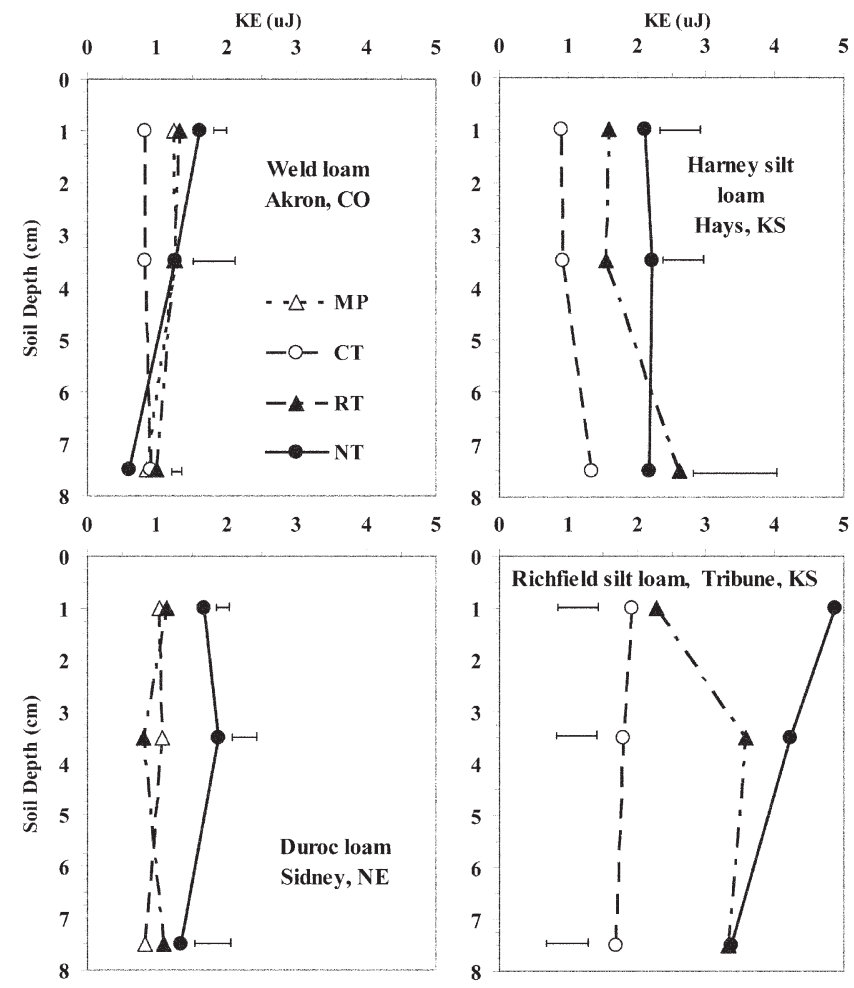

Fig. 1. Mean kinetic energy (KE) required to disintegrate 4.75- to $8-\mathrm{mm}$ air-dry $(-155 \mathrm{MPa})$ aggregates by depth and tillage system for four soils in the central Great Plains. Errors bars are the LSD values for comparing differences in KE for each depth interval.

aggregate. Aggregates with WDPT $<1 \mathrm{~s}$ were classified as non-water repellent while those with WDPT between 1 and $10 s$ as very low repellent and those with WDPT between 10 and $60 \mathrm{~s}$ as low repellent (King, 1981). Thirty individual aggregates per treatment replication and depth interval for each soil were used for the raindrop and wettability tests for a total of 7020 aggregates. For determination of dry aggregate stability, $50 \mathrm{~g}$ of 4.75 - to 8 -mm air-dry aggregates were sieved through a column of sieves with 4.75-, 2-, 1-, 0.5-, and 0.25-mm openings for $30 \mathrm{~min}$ (Nimmo and Perkins, 2002). Soil retained in each sieve was weighed to compute the MWD. The soil particle-size distribution was determined by the hydrometer method for the 0 - to 2-cm depth (Gee and Or, 2002). The SOC content was determined by the dry combustion method $\left(900^{\circ} \mathrm{C}\right)$ using a CN analyzer (Nelson and Sommers, 1996) on air-dried samples sieved through a 0.25 -mm mesh.

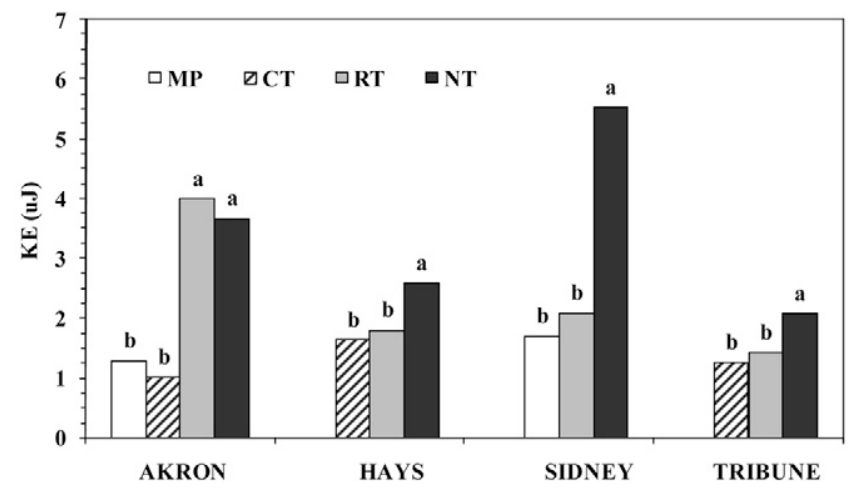

Fig. 2. Mean kinetic energy (KE) required to disintegrate 4.75- to 8-mm aggregates equilibrated at $-0.03 \mathrm{MPa}$ for the $0-$ to $2-\mathrm{cm}$ depth by tillage system for four soils in the central Great Plains. Bars followed by the same lowercase within each soil of the four soils are the LSD values for comparing differences in KE of raindrops.
Statistical differences in the measured aggregate parameters among tillage treatments were tested using a one-way ANOVA model. Simple regression models and correlations among measured parameters were performed by soil and across all soils. All data analyses were conducted using SAS statistical software (SAS Institute, Inc., 2008). Statistical differences were discussed at the 0.05 probability level.

\section{RESULTS AND DISCUSSION Aggregate Properties that Influence Soil Erodibility by Water}

No-till management significantly impacted aggregate resistance to raindrops and aggregate wettability across the four soils (Fig. 1, 2, and 3). The KE of raindrops required to break individual $(4.75-8 \mathrm{~mm})$ air-dry $(-155 \mathrm{MPa} \psi)$ aggregates from NT soils was consistently greater than that required for aggregates from MP and CT soils (Fig. 1). The KE of raindrops needed for aggregate disintegration in NT soils was about two times greater than in plowed soils in the $0-$ to 5 -cm depth in all soils except at Akron where it was about 1.5 times greater. At Tribune, NT management increased the KE for air-dry aggregate disintegration at all depth intervals from 0 to $10 \mathrm{~cm}$ (Fig. 1). The KE for air-dry aggregate disintegration between RT and CT did not differ in most soils, but it was two times greater in RT than in CT soil at Tribune in the 2- to 10-cm depth.

No-till management also impacted aggregate disintegration at $-0.03 \mathrm{MPa}$ (field capacity) as shown in Fig. 2. Compared with $\mathrm{MP}$ and $\mathrm{CT}$ soils, the KE for disintegration of aggregates equilibrated at $-0.03 \mathrm{MPa}$ in NT was four times greater at Akron, three times greater at Sidney, and 1.5 times greater at Hays and Tribune in the 0 - to 2-cm depth (Fig. 2). These results showed
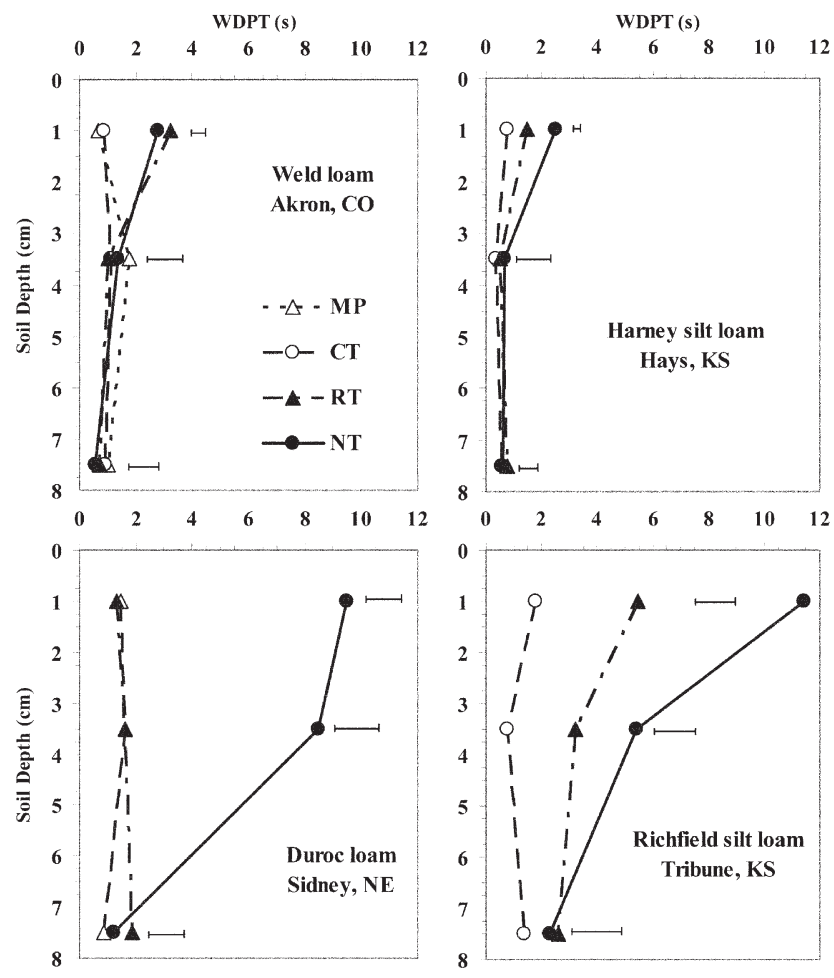

Fig. 3. Geometric mean water drop penetration test (WDPT) for 4.75to 8-mm air-dry (-155 MPa) aggregates by depth and tillage system for four soils in the central Great Plains. Errors bars are the LSD values for comparing differences in KE for each depth interval. 
that the KE of raindrops needed to disintegrate soil aggregates at Akron and Sidney were greater for aggregates at field capacity than at air-dry conditions. This is attributed to the reduced slaking of wet aggregates as compared with air-dry aggregates as lesser pore space is available in wet aggregates for air entrapment.

Log-transformation was used to normalize the data on WDPT, and geometric means are reported in Fig. 3. The WDPT values for these soils were always greater for NT than those for MP and CT in the 0 - to 2-cm depth (Fig. 3). No-till management slowed water entry into the aggregates as compared with MP and CT in the 0 - to 2-cm depth. At this depth, the WDPT in NT soils was four times greater at Akron and Hays and seven times greater at Sidney and Tribune compared with plowed soils. The WDPT values averaged across soils at Akron and Hays were $2.5 \mathrm{~s}$ for NT and $0.6 \mathrm{~s}$ for MP and CT, whereas those at Sidney and Tribune were $11 \mathrm{~s}$ for NT and $1.5 \mathrm{~s}$ for MP and CT (Fig. 3) in the 0- to 2-cm depth. No-till management had greater impact on slowing water entry into aggregates at Sidney and Tribune in the $0-$ to $5-\mathrm{cm}$ depth (Fig. 3). The RT management also slowed water entry into aggregates compared with CT at Akron in the 0- to 2-cm depth and at Tribune in the 0 - to 5-cm depth. As expected, differences in aggregate wettability among tillage treatments decreased with soil depth and were not significant below the 5-cm depth (Fig. 3). Based on the classification by King (1981), MP and CT soils were non-water repellent whereas NT soils were very low water repellent. The RT soils at Akron and Tribune were also classified as very low water repellent and those at Hays and Sidney as nonwater repellent. The greater WDPT in NT than in CT across the four soils in this semiarid region is in accord with the study by Blanco-Canqui and Lal (2009) who observed that WDPT in NT was greater than in CT by about $5 \mathrm{~s}$ in 8 of 12 soils in a temperate region in the eastern USA. Thus, these studies show that slight water repellency in NT systems is a widespread phenomenon.

The greater aggregate stability against raindrops in NT soils is partly attributed to reduced aggregate wettability (Capriel, 1997; Ellerbrock et al., 2005). The small delay in water entry in NT soils (Fig. 3) probably had a large effect on increasing aggregate resistance to raindrops by reducing air entrapment that causes rapid aggregate slaking (Chenu et al., 2000; BlancoCanqui et al., 2007). Indeed, the $\mathrm{KE}$ of raindrops needed to disrupt aggregates was positively correlated with aggregate wettability, which explained $44 \%$ of the variability in KE at Akron, $39 \%$ at Hays, $52 \%$ at Sidney, $46 \%$ at Tribune, and $47 \%$ across all soils in the surface layer (Fig. 4). The results of this study showed that aggregates from NT soils were generally more stable against raindrops and less wettable than those from MP and CT soils.

Mixing of surface soil with subsoil caused by tillage and increased erosion may modify the soil particle-size distribution in CT management compared with NT management. In this study, differences in soil particle-size fractions among tillage systems were not significant in any soil except at Sidney and Hays. The silt content in CT soil was greater at Akron ( 460 vs. $414 \mathrm{~g} \mathrm{~kg}^{-1}$ ) and Sidney ( 496 vs. $328 \mathrm{~g} \mathrm{~kg}^{-1}$ ) than in NT soil. Similarly, the clay content in CT $\left(394 \mathrm{~g} \mathrm{~kg}^{-1}\right)$ soil was greater than in NT $\left(336 \mathrm{~g} \mathrm{~kg}^{-1}\right)$ soil at Hays. Aggregates from the CT soil at Hays were, however, less stable under rain in spite of their greater clay content compared with those from the NT soil.

The large differences in aggregate resistance to raindrops between NT and CT systems across the four soils are in line with the findings by Blanco-Canqui et al. (2007) who reported that the kinetic energy required to break aggregates from a NT soil under continuous corn (Zea mays L.) was about sevenfold greater than that in a CT soil in Ohio. Results also indicate that the raindrop technique is sensitive at detecting differences in wet-aggregate stability among tillage systems and underscore the need for comparing this technique against the wet-sieving approach to discern NT-induced impacts on wet-aggregate stability. We hypothesize that the raindrop technique may be a simpler alternative to the wet-sieving approach once the results from the raindrop test are standardized against those from the wet-sieving approach. The raindrop technique has been previously used to determine soil erodibility by water (Bruce-Okine and Lal, 1975; Al-Durrah and Bradford, 1981).

\section{Aggregate Properties that Influence Soil Erodibility by Wind}

No-till management did not induce any significant differences in dry aggregate-size distribution and stability except at Akron where MWD of dry aggregates in MP was greater by about 1.5 times than in RT and NT management in the 0 - to 2 -cm depth interval (Fig. 5). The small or no effects of NT management on dry aggregate stability contrasted with its large and positive impacts on aggregate wettability and resistance to breakdown under raindrops. The limited influence of NT management on dry aggregate stability was not, however, highly surprising. Past studies in the Great Plains have also found small or no effects of
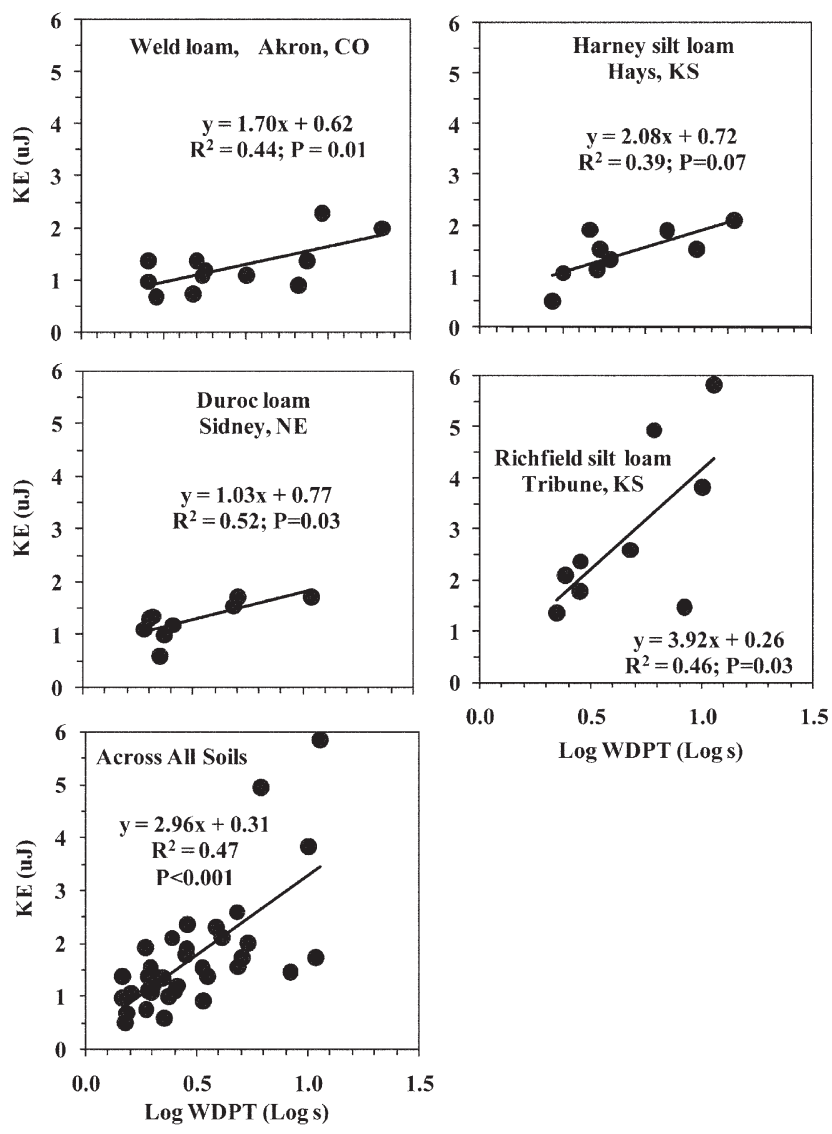

Fig. 4. Relationship between mean kinetic energy (KE) required to disintegrate 4.75 - to 8-mm air-dry (-155 $\mathrm{MPa}$ ) aggregates and $\log$ water drop penetration test (Log WDPT) for four soils in the central Great Plains. 

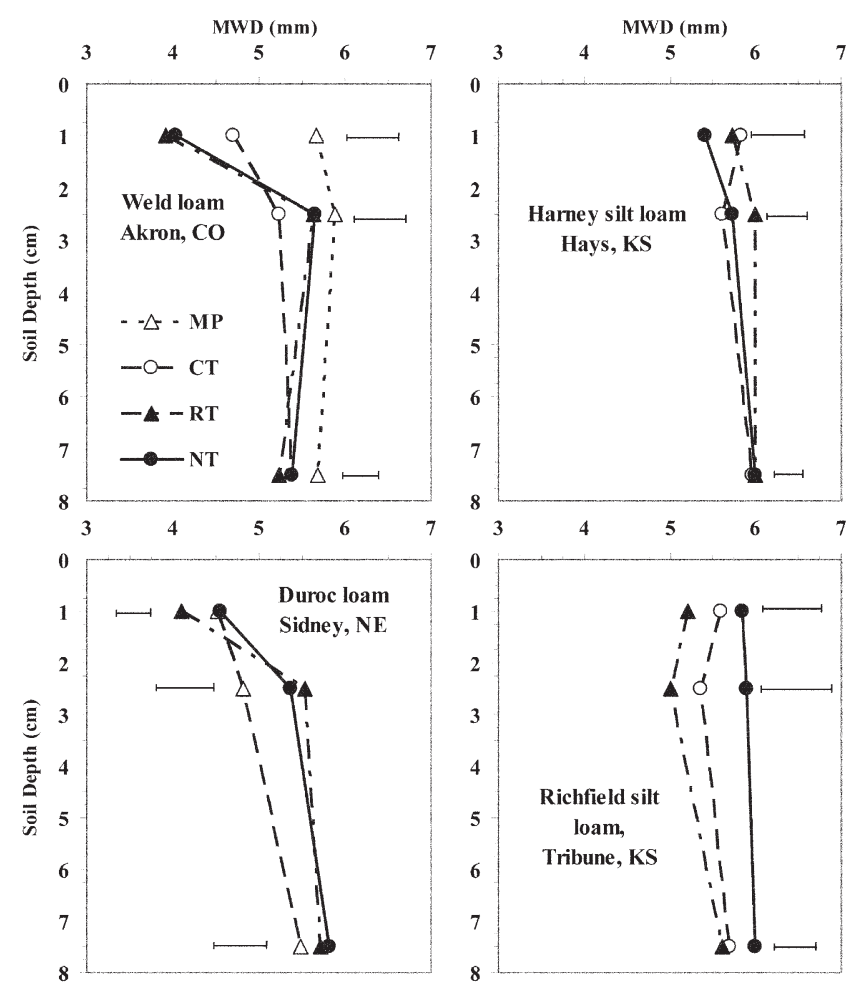

Fig. 5. Mean weight diameter (MWD) of dry aggregates by depth and tillage system for four soils in the central Great Plains. Errors bars are the LSD values for comparing differences in KE for each depth interval.

NT management on dry aggregate stability. For the same tillage experiment at Hays, Layton et al. (1993) observed that dry aggregates in the NT soil were either less stable or equal to compared with CT soil. On a clay loam in the southern Great Plains, Unger (1982) found no differences in MWD of dry aggregates among three tillage systems (disk, mulch, and delayed mulch) after 36 yr of management. Pikul et al. (2006) also found small or no effects of RT on dry aggregate stability compared with CT across various soils in the Great Plains. In contrast, Eynard et al. (2004) observed that dry MWD in NT was 32\% greater than in CT in various soils in central South Dakota. Previous work shows that impacts of tillage systems on dry aggregate stability can vary, depending on soil type, cropping system, and climate.

Despite the lack of significant differences in dry aggregate stability between NT and plowed systems, soil wind erodibility is expected to be lower in NT systems because these soils normally remain under crop residue cover unlike CT soils where residues are plowed under. Results on dry aggregate stability suggest the strong need for maintaining surface residue cover (e.g., standing stalks) on the soil surface. We hypothesize that in some NT soils with reduced or no residue cover, wind erosion can be even greater than in plowed soils, particularly during drought periods, because of absence of transient large clods or surface roughness created by tillage. Visual observation for the soil at Akron showed reduced residue cover in NT soils compared with NT soils in temperate regions (Blanco-Canqui et al., 2007), which may explain the lower dry aggregate stability but the differences in surface residue cover was not quantified in this study. Our results agree partly with those reported by Skidmore et al. (1986) who observed that wheat or sorghum residue incorporated, removed, and burned did not affect dry aggregate stability in a silty clay loam in southwestern Kansas.
Data on aggregate properties, particularly those from Akron, showed that aggregates under MP soil were stronger when dry but were weaker or less stable when wet compared with NT soil. These results support those observed by Blanco-Canqui et al. (2007) in soils in temperate regions where tensile strength of dry aggregates for MP was greater than for NT but collapsed more rapidly when submerged in water. Such results indicate that the greater SOC-enriched materials in NT may have a more positive impact on stabilizing wet aggregates than dry aggregates due to greater adhesive (e.g., glue-like binding substances) forces of organic materials acting in wet aggregates (Tisdall and Oades, 1982). Drying causes contraction of soil aggregates forming hard aggregates (Haynes, 2000), which may outweigh any differences in dry aggregate stability among tillage treatments. Additional soil properties such as $\mathrm{pH}, \mathrm{CaCO}_{3}$, cation exchange capacity, and exchangeable sodium percentage should be characterized to explain the lack of differences in dry aggregate stability among tillage systems (Amezketa, 1999).

The greater clay content in $\mathrm{CT}$ resulting from soil mixing compared with that in NT at Hays may have increased the cohesive forces of particles of dry aggregates (Layton et al., 1993), but these aggregates were readily detached under rain, probably, because of their lower SOC content, smaller microbial biomass, and weaker biological bonding forces (Bronick and Lal, 2005). A study across 10 soils in Kansas by Skidmore and Layton (1992) showed that clay content was one of the most sensitive predictors of dry aggregate stability. The differential physical, chemical, and biological mechanisms by which organic and inorganic particles bind dry and wet aggregates in these soils deserve further research. It is also important to note that while there was no effect of the tillage systems on dry aggregate stability there may be an interactive effect between rainstorms and dry aggregate-size fractions under field conditions. The greater disintegration of aggregates under the impacting raindrops in CT soils, as discussed earlier, may increase the proportion of wind erodible dry aggregates (particles $<0.80 \mathrm{~mm}$ diam.) after the soil dries out following a rainstorm.

\section{Relationship between Aggregate Properties and Soil Organic Carbon}

The near-surface aggregate properties were significantly correlated with SOC content. The SOC content in NT was greater than in MP at Akron and CT at Hays in the 0- to 2-cm depth (Fig. 6). At Sidney, SOC content in NT was greater than in MP for all depth intervals (0- to 2-, 2- to 5-, 5- to 10-cm depths). At Sidney, SOC content in RT was also lower than in NT in the 0 - to $5-\mathrm{cm}$ zone. Differences in SOC content among tillage systems were not significant at Tribune (Fig. 6).

The greater number of raindrops needed to destroy aggregates in NT soils was due, in part, to the greater SOC content in most NT soils compared with plowed soils. Figure 7 shows that $\mathrm{KE}$ of raindrops for disintegration of air-dry aggregates increased positively with the increase in SOC content in all soils in the $0-$ to $2-\mathrm{cm}$ depth. The NT-induced increases in SOC content explained nearly $50 \%$ of the variability in aggregate resistance to raindrops for the soils in Hays, Sidney, and Tribune and $35 \%$ for soil at Akron (Fig. 7). Results suggest that SOCenriched materials in NT soils probably acted as strong binding agents to glue soil particles and created aggregates stable against raindrops (Tisdall and Oades, 1982). The moderate correlations 
of aggregate resistance to raindrops and wettability with SOC may be due to the relatively small increases in SOC with NT in this climate. Stronger correlations between soil structural properties and SOC are often observed in soils of humid regions with greater gains in SOC with NT (Blanco-Canqui et al., 2007).

Aggregate wettability was also positively and significantly correlated with SOC content in all soils except at Akron where the correlation was not significant (Fig. 8). Changes in SOC content explained $66 \%$ of the variability in WDPT at Hays, 69\% at Sidney, 53\% at Tribune, and 35\% across all soils. These results suggest that SOC increase with NT improved aggregate resistance to raindrops by inducing slight water repellency and by binding soil particles into stable aggregates. Unlike the significant and positive correlations between aggregate properties and SOC content, aggregate properties were more weakly correlated with soil particle-size fractions than with SOC content. The regression equations developed across the four soils showed that SOC was the most significant predictor of the KE of raindrops needed for aggregate disintegration (Eq. [3]) and aggregate wettability (Eq. [4])

$$
\mathrm{KE}=-1.83+0.11 \mathrm{SOC}+0.005 \text { Silt }, \quad r^{2}=0.34, \quad P=0.002
$$

WDPT $=0.06+0.09$ SOC -0.0002 SOC $\times$ Clay,

$r^{2}=0.41, P=0.002$

where SOC, silt, and clay content are expressed in $\mathrm{g} \mathrm{kg}^{-1}$.
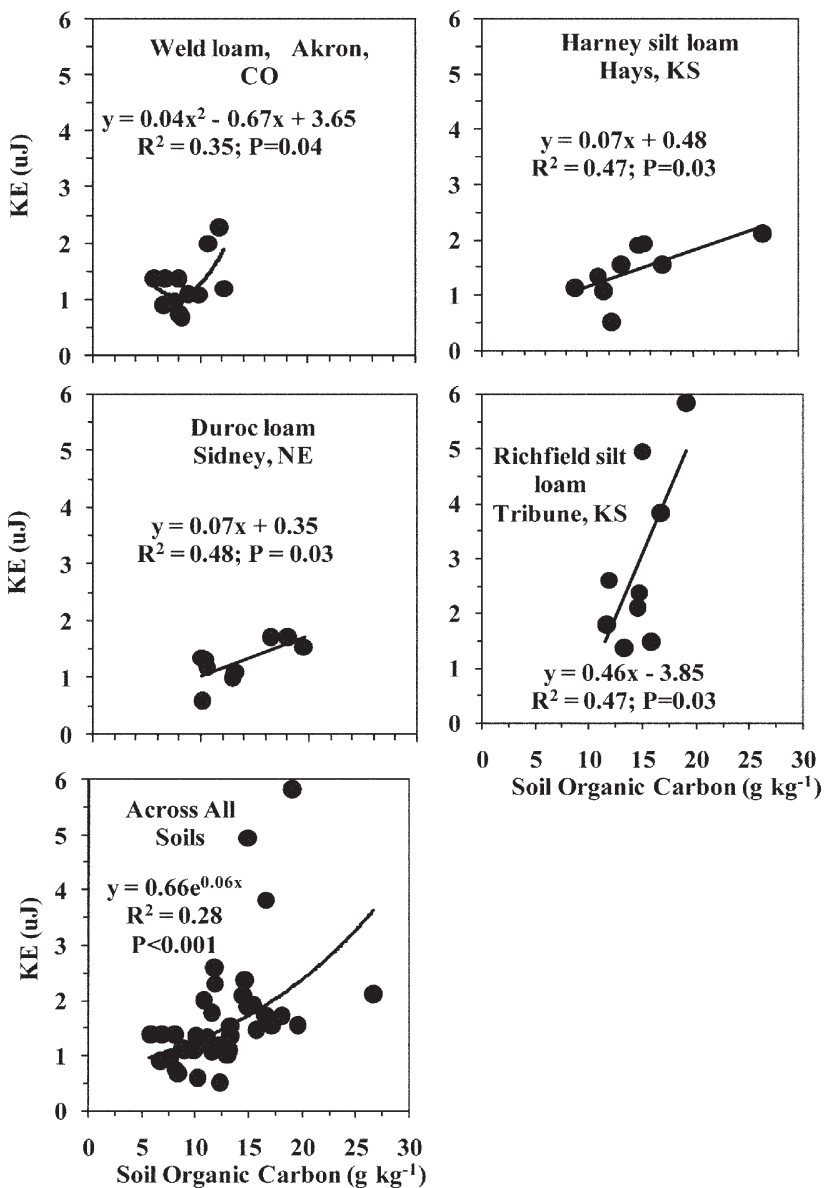

Fig. 7. Relationship between mean kinetic energy (KE) required to disintegrate 4.75- to 8-mm air-dry (-155 MPa) aggregates and soil organic carbon content for four soils in the central Great Plains.
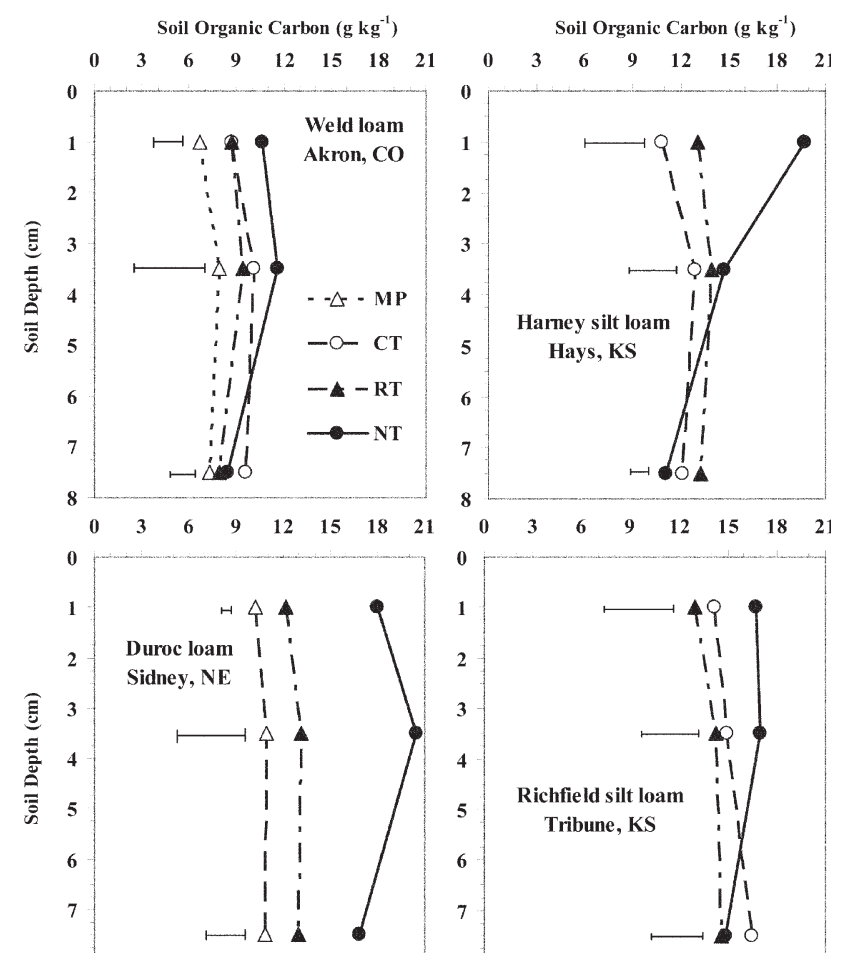

Fig. 6. Mean soil organic $C$ by depth and tillage system for four soils in the central Great Plains. Errors bars are the LSD values for comparing differences in KE for each depth interval.
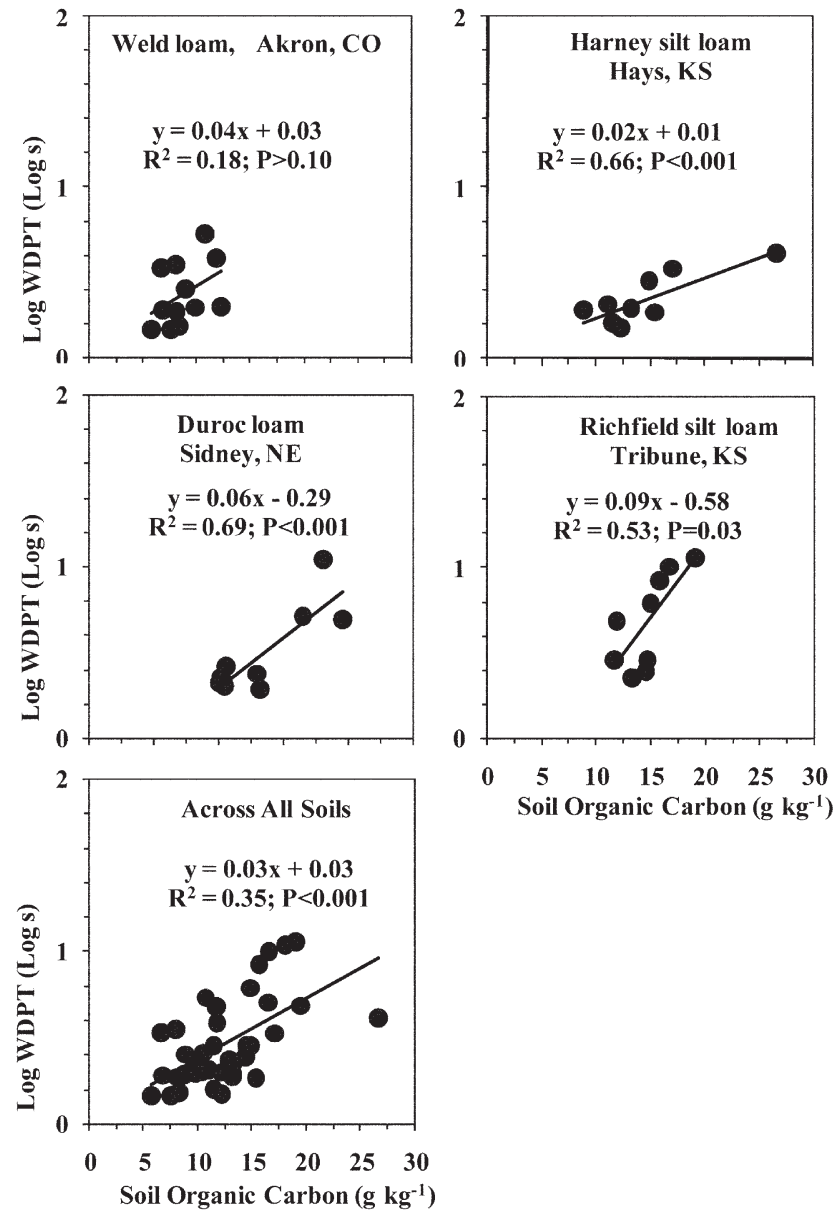

Fig. 8. Relationship between log water drop penetration test (Log WDPT) and soil organic carbon content for four soils in the central Great Plains. 
The MWD of dry aggregates was not significantly correlated with changes in SOC at any of the four soils.

\section{CONCLUSIONS}

Results from this regional study across the central Great Plains show that NT management modified near-surface soil aggregate parameters such as aggregate water repellency and resistance to breakdown by raindrops as compared with plowed soils. The increase in SOC content is partly responsible for the greater aggregate water repellency, stability, and resistance to raindrops under NT soils. The increased aggregate water repellency due to increased SOC content further enhances aggregate resistance to raindrops in NT soils. Aggregates of NT soils are more stable when wet and less or equally stable when dry than those in plowed soils. The significantly lower aggregate resistance to raindrops under plowed soils is attributed to the frequent soil disturbance that creates weak aggregates by disrupting aggregation and accelerating oxidation of soil organic matter. Reduced till has lesser beneficial impacts than NT systems on improving soil aggregate properties. The magnitude at which NT farming enhances near-surface aggregate properties and SOC accumulation across the central Great Plains is soil-specific and depends on soil aggregate properties. No-till management appears to have small or no effects on dry aggregate-size distribution and stability. Overall, the positive effects of NT on aggregate wettability and resistance against raindrop impacts support the advantages of NT technology to improving soil structure and reducing soil erodibility by water, but NT management does not improve aggregate properties that influence erosion by wind.

\section{REFERENCES}

Al-Durrah, M., and J.M. Bradford. 1981. New methods of studying soil detachment due to waterdrop impact. Soil Sci. Soc. Am. J. 45:949-953.

Amezketa, E. 1999. Soil aggregate stability: A review. J. Sustain. Agric. 14:83-151.

Benjamin, J.G., M.M. Mikha, and M.F. Vigil. 2008. Organic carbon effects on soil physical and hydraulic properties in a semiarid climate. Soil Sci. Soc. Am. J. 72:1357-1362.

Blanco-Canqui, H., and R. Lal. 2009. The extent of soil water repellency under long-term no-till soils. Geoderma 149:171-180.

Blanco-Canqui, H., R. Lal, and M.J. Shipitalo. 2007. Aggregate disintegration and wettability for long-term management systems in the northern Appalachians. Soil Sci. Soc. Am. J. 71:759-765.

Blanco-Canqui, H., and R. Lal. 2004. Mechanisms of carbon sequestration in soil aggregates. Crit. Rev. Plant Sci. 23:481-504.

Bronick, C.J., and R. Lal. 2005. Soil structure and management: A review. Geoderma 124:3-22.

Bruce-Okine, E., and R. Lal. 1975. Soil erodibility as determined by raindrop technique. Soil Sci. 119:149-157.

Capriel, P. 1997. Hydrophobicity of organic matter in arable soils: Influence of management. Eur. J. Soil Sci. 48:457-462.

Chenu, C., Y. Le Bissonnais, and D. Arrouays. 2000. Organic matter influence on clay wettability and soil aggregate stability. Soil Sci. Soc. Am. J. 64:1479-1486.

Chepil, W.S. 1954. Seasonal fluctuations in soil structure and erodibility of soil by wind. Soil Sci. Soc. Am. Proc. 18:13-16.

Dane, J.H., and J.H. Hopmans. 2002. Water Retention and Storage. p. 671-717. In J.H. Dane and G. C. Topp (ed.) Methods of soil analysis. Part 4. Agron. Monogr. 5. SSSA, Madison, WI.

DeBano, L.F. 2000. The role of fire and soil heating on water repellency in wildland environments: A review. J. Hydrol. 231:195-206.

Ellerbrock, R.H., H.H. Gerke, J. Bachmann, and M.-O. Goebel. 2005. Composition of organic matter fractions for explaining wettability of three forest soils. Soil Sci. Soc. Am. J. 69:57-66.

Eynard, A., T.E. Schumacher, M.J. Lindstrom, and D.D. Malo. 2004. Aggregate sizes and stability in cultivated South Dakota prairie Ustolls and Usterts. Soil Sci. Soc. Am. J. 68:1360-1365.

Gee, G.W., and D. Or. 2002. Particle-size analysis. p. 255-293. In J.H. Dane and G. C. Topp (ed.) Methods of soil analysis. Part 4. SSSA Book Ser. 5. SSSA, Madison, WI.

Hallett, P.D., T. Baumgartl, and I.M. Young. 2001. Subcritical water repellency of aggregates from a range of soil management practices. Soil Sci. Soc. Am. J. 65:184-190.

Haynes, R.J. 2000. Interactions between soil organic matter status, cropping history, method of quantification and sample pretreatment and their effects on measured aggregate stability. Biol. Fertil. Soils 30:270-275.

Hudson, N. 1995. Soil conservation. 3rd ed. Iowa State Univ. Press, Ames.

King, P.M. 1981. Comparison of methods for measuring severity of water repellence of sandy soils and assessment of sandy soils and assessment of some factors that affect its measurement. Aust. J. Soil Res. 19:275-285.

Layton, J.B., E.L. Skidmore, and C.A. Thompson. 1993. Winter-associated changes in dry-soil aggregation as influenced by management. Soil Sci. Soc. Am. J. 57:1568-1572.

Letey, J., M.L.K. Carrillo, and X.P. Pang. 2000. Approaches to characterize the degree of water repellency. J. Hydrol. 231:61-65.

Lyon, D.J., W.W. Stroup, and R.E. Brown. 1998. Crop production and soil water storage in long-term winter wheat-fallow tillage experiments. Soil Tillage Res. 49:19-27.

Mbagwu, J.S.C., and P. Bazzoffi. 1998. Soil characteristics related to resistance of breakdown of dry soil aggregates by water-drops. Soil Tillage Res. 45:133-145.

McVay, K.A., J.A. Budde, K. Fabrizzi, M.M. Mikha, C.W. Rice, A.J. Schlegel, D.E. Peterson, D.W. Sweeney, and C. Thompson. 2006. Management effects on soil physical properties in long-term tillage studies in Kansas. Soil Sci. Soc. Am. J. 70:434-438.

Merrill, S.D., A.L. Black, D.W. Fryrear, A. Saleh, T.M. Zobeck, A.D. Halvorson, and D.L. Tanaka. 1999. Soil wind erosion hazard of spring wheat-fallow as affected by long-term climate and tillage. Soil Sci. Soc. Am. J. 63:1768-1777.

Munkholm, L.J., and B.D. Kay. 2002. Effect of water regime on aggregate tensile strength, rupture energy, and friability. Soil Sci. Soc. Am. J. 66:702-709.

Nelson, D.W., and L.E. Sommers. 1996. Total carbon, organic carbon, and organic matter: Laboratory methods. p. 961-1010. In D.L. Sparks et al (ed.) Methods of soil analysis. Part 3. SSSA Book Ser. No. 5. SSSA and ASA, Madison, WI.

Nimmo, J.R., and K.S. Perkins. 2002. Aggregate stability and size distribution. p. 317-327. In J.H. Dane and G. C. Topp. (ed.) Methods of soil analysis. Part 4. Agron. Monogr. 5. SSSA, Madison, WI.

Pikul, J.L., R.C. Schwartz, J.G. Benjamin, R.L. Baumhardt, and S. Merrill. 2006. Cropping system influences on soil physical properties in the Great Plains. Renew. Agric. Food Syst. 21:15-25.

SAS Institute, Inc. 2008. Online doc. 9.1.3. Available online at http://support. sas.com/onlinedoc/913/docMainpage.jsp (verified 16 Apr. 2009) SAS Institute, Inc., Cary, NC.

Skidmore, E.L., and J.B. Layton. 1992. Dry-soil aggregate stability as influenced by selected soil properties. Soil Sci. Soc. Am. J. 56:557-561.

Skidmore, E.L., J.B. Layton, D.V. Armbrust, and M.L. Hooker. 1986. Soil physical properties as influenced by cropping and residue management. Soil Sci. Soc. Am. J. 50:415-419.

Tisdall, J.M., and J.M. Oades. 1982. Organic matter and water stable aggregates in soils. J. Soil Sci. 33:141-163.

Unger, P.W. 1982. Surface soil properties after 36 years of cropping to winter wheat. Soil Sci. Soc. Am. J. 46:796-801.

Wagner, S., S.R. Cattle, and T. Scholten. 2007. Soil-aggregate formation as influenced by clay content and organic-matter amendment. J. Plant Nutr. Soil Sci. 170:173-180. 